\title{
A PILOT STUDY OF SENSITIZATION TO PLANE TREE POLLEN IN SOFIA, BULGARIA
}

\author{
Georgi Nikolov ${ }^{1}$, Rusana Tsvetanova ${ }^{2}$, Mariela Hristova- Savova ${ }^{1}$ \\ 1) National Centre of Infectious and Parasitic Diseases, Department of \\ Immunology, Sofia, Bulgaria \\ 2) Department of Landscape Architecture, Faculty of Ecology and Landscape \\ Architecture, University of Forestry, Sofia, Bulgaria.
}

\section{ABSTRACT}

Purpose: Platanus pollen is a serious cause of asthma, allergic rhinitis and conjunctivitis in many European countries. The aim of the present pilot study is to investigate the sensitization to 3 different plane tree species in a group of patients with pollinosis.

Materials and methods: 21 patients were surveyed - 11 men and 10 women. A skin prick test was performed with a set of allergens: Grass pollen mix; Betulaceae pollen mix; Platanusorientalis; Platanusacerifolia; Platanusoccidentalis.

Results: $95 \%$ of patients are sensitized to grass pollen, with moderate positive skin reactions predominating. $86 \%$ have a co-sensitization to tree pollens also, particularly to the birch tree family. Only 3 (14\%) of the studied patients showed slight positive skin tests to the studied plane tree allergens, with no significant difference in sensitization to studied Platanus species $(p>0,05)$.

Conclusion: At present, the sensitization to different Platanus species is not comparable to that of grass or birch pollen. However, it will be necessary to conduct new long-term, large-scale studies to prove whether Platanus pose a real threat to people in urban areas.

The results of this interdisciplinary study are important both for clinical allergologists and for landscape architects and ecologists involved in the planning and management of urban green infrastructure.

Keywords: pollen allergy, Platanus allergy, pollinosis, skin prick tests,

\section{INTRODUCTION}

Pollinosis (hay fever) is the most common form of IgE-mediated allergy in Europe, and the number of people affected is increasing every year. Pollen allergy is one of the biggest health problems, significantly affecting the world economy, especially in the conditions of constantly changing climate[1,14].

Species of the genus Platanus form a significant amount of pollen and are considered a significant inhalant allergen in many countries around the world.
The plane trees bloom in the spring and produce a significant amount of pollen [2]. Their pollen spreads quickly, anemophilically and over long distances, and it was found that PlatanusorientalisL.is one of the species with the largest amount of pollen in the inflorescence: 3.3 $\times 10^{6} \pm 0.2 \times 10^{6}[3]$.

As early as 1970, plane trees were shown to cause sensitization. Platanus pollen is a serious cause of asthma, allergic rhinitis and conjunctivitis [4, 5]. Strong cross-reactivity often occurs between plane trees and different types of plant food [6].

In our country, the genus Platanus L. is represented by three species: Platanusorientalis L., Platanusoccidentalis L. and Platanusacerifolia (Aiton) Willd., which is a hybrid obtained from the first two species. The hybrid is the plane species that has been increasingly used in landscape practice in Bulgaria [7].

Every year a large number of young trees of the species are planted. Cariñanos et al. [8] emphasize that the benefits of using plane trees in urban landscaping are undeniable, but the negative effects of this must also be assessed so as not to upset the balance between the ecosystem services provided by species on the one hand and the negative impact on the environment.

In Bulgaria, only partial up-to-date information can be found on the distribution of the genus Platanus $\mathrm{L}$ in public green areas $[9,10]$, but so far, no studies have been conducted on the allergenic potential of plane tree pollen. In this regard, the aim of the present pilot study is to investigate the sensitization to 3 different plane tree species in a group of patients with pollinosis.

\section{MATERIALS AND METHODS \\ Study location}

Following the example of different countries in Europe, where similar studies have been conducted (Spain, Greece, Turkey etc.), the first study in our country is conducted in Sofia. The location was not chosen by chance because in Sofia, as the European capital, the density of plane trees is the highest; there is serious air pollution, which affects the manifestation of allergies, and a large part of the population shows sensitivity to pollens. 


\section{Pollen data}

Aerobiological data in the atmosphere of Sofia were collected from February to October foran 8-years period (between 2013 and 2020). The method was based on free sedimentation of pollen grains from the air. A glass slide covered with adhesive material was situated for $24 \mathrm{~h}$ in an outdoor area 10 meters above the ground. The pollen deposition on $3.24 \mathrm{sm}^{2}$ square of the slide was counted manually and determinate microscopically. Thus, the quantities of pollen grains of the main plant families Poaceae and Betulaceae, as well as of the genus Platanus L., have been studied. The results are presented as the average number of pollen grains per year.

\section{Patients}

The sensitization to the most spread Platanusspecies in Bulgaria was studied in a group of patients with a manifestation of seasonal allergic rhinitis (pollinosis) in months March - June.

About 21 patients were surveyed - 11 men and 10 women between the ages of 22 and 59.

After obtaining informed consent, project participants complete a specially designed questionnaire. Each participant was then subjected to a detailed allergic examination to determine the presence of allergic complaints during the pollen season.

\section{Skin prick tests with allergens from different} Platanus species

Specific sensitization to pollens of 3 most spread plane tree species: Platanusorientalis L. (Oriental plane); Platanus $x$ acerifolia (Aiton) Willd. (London plane) and Platanusoccidentalis L. (American sycamore) was assessed by allergy skin prick tests (SPT).

For this purpose, in the Laboratory for Allergenic preparations at Bul Bio NCIPD, Sofia, Bulgaria, special diagnostic allergens from the above mentioned Platanus species were prepared.

As a raw material for the production of allergenic extracts, plane tree pollen was collected and provided by scientists from the University of Forestry, Sofia.

Allergens were prepared by an original methodology consistent with the procedures for the production and standardization of pollen allergens for diagnosis by SPT, complying with the requirementsof Good Manufacturing Practice (GMP).

A control group of 21 volunteers (11 healthy, nonallergic individuals and 10 patients, sensitized to house dust mites) was tested with the above mentioned experimental extracts by Prick test and showed no positive skin reactions,so we can prove the specificity of the allergens from studiedPlatanusspecies,

To confirm the specific sensitization of patients, we performeda skin allergy test (prick test) with a set of allergens, Bul Bio NCIPD ltd., which includes:

B1. Grass pollen mix $1000 \mathrm{PNU} / \mathrm{ml}$ (Dactylisglomerata, Festuca sp., Loliumperenne, Secalecereale, Phleum pretense, Poa sp., Holcuslanatus, Agrostis alba, Bromus sp., Alopecurus sp., Agropyronrepens, Arrhenatherumelatius,Zea mays, Deschampsiacaespitosa);

$\mathrm{B} 2^{\mathrm{I}}$. Betulaceae tree pollen mix $1000 \mathrm{PNU} / \mathrm{ml}$
(Corylusavellana, Betulapendula, Alnus sp., Carpinusbetulus);

B57-1.Platanusorientalis $1000 \mathrm{PNU} / \mathrm{ml}$;

B57-2.Platanusacerifolia $1000 \mathrm{PNU} / \mathrm{ml}$;

B57-3.Platanusoccidentalis $1000 \mathrm{PNU} / \mathrm{ml}$.

The diagnostic allergy skin tests were performed simultaneously in a volume of $0.05 \mathrm{ml}$ on the volar side of the forearm of each participant. Negative (Coca I solution) and positive (histamine $1 \mathrm{mg} / \mathrm{ml}$ ) controls were applied in parallel.

The reactions obtained were read at 20 minutes according to the size of the wheal and flare. Size of wheal and flare with a mean diameter $>3 \mathrm{~mm}$ were considered positive.

To determine the degree of skin reaction to the allergen we use, following grading scale, based on the size of the wheal (Table 1.).

Table 1. Degree of skin reaction to the allergens

\begin{tabular}{|l|l|}
\hline Wheal size $\mathbf{( m m )}$ & Interpretation of skin reaction \\
\hline$<3$ & Negative \\
\hline $3-5$ & Slight positive \\
\hline $5-10$ & Moderate positive \\
\hline $10-15$ & Strong positive \\
\hline$>15$ & Very strong positive \\
\hline
\end{tabular}

\section{Statistics}

All analyses were performed using the software package GraphPad Prism 6.0 (GraphPad Software, Inc.). Descriptive analysis of the wheal areas in SPT was performed as well as comparisons of means and ratios by Mann-Whitney test of unpaired t test data. Probability values of $p<0.05$ were considered statistically significant.

\section{RESULTS}

The summarized aerobiological data show that the pollens of the Betulaceae family predominate in the air of Sofia with average quantities of 7790 grains during the years under monitoring, followed by the grass pollen - 1922 grains. The registered amount of pollen from trees of the genus PlatanusL.is the lowest - an average of 191 pollen grains per year (Table 2.).

Table 2.Number of pollen grains for the last 8 years (average number per year)

\begin{tabular}{|c|c|c|c|}
\hline Year/Taxon & Betulaceae & Poaceae & Platanus sp. \\
\hline $\mathbf{2 0 1 3}$ & 3332 & 1445 & 57 \\
\hline $\mathbf{2 0 1 4}$ & 5254 & 1651 & 93 \\
\hline $\mathbf{2 0 1 5}$ & 5230 & 3537 & 124 \\
\hline $\mathbf{2 0 1 6}$ & 15179 & 2596 & 113 \\
\hline $\mathbf{2 0 1 7}$ & 3735 & 1632 & 356 \\
\hline $\mathbf{2 0 1 8}$ & 8945 & 1646 & 374 \\
\hline $\mathbf{2 0 1 9}$ & 4111 & 1310 & 221 \\
\hline $\mathbf{2 0 2 0}$ & 16530 & 1559 & 188 \\
\hline Average & $\mathbf{7 7 9 0}$ & $\mathbf{1 9 2 2}$ & $\mathbf{1 9 1}$ \\
\hline
\end{tabular}


However, the detailed analysis of the data for plane trees pollen showed that in the last 4 years (from 2017 to $2020)$, there has been a statistically significant $(p<0.05)$ increase in the number of pollen grains in the air of Sofia and their quantity is doubled.

Skin allergy tests revealed that of the 21 patients with pollen allergy, 3 (14\%) were monosensitized: 2 to grass pollen and 1 to birch pollen. No monosensitization to plane tree allergens was observed.

The remaining $18(86 \%)$ patients showed polysensitization to different pollen allergens. $13(72 \%)$ were sensitized to 2 allergens (grass and birch pollen), and 5 (28\%) showed sensitization to more than 2 allergens.

The majority of patients (95\%) are sensitized to grass pollen, with moderate positive skin reactions predominating (Fig. 1).

Fig. 1.Sensitization and degree of skin reaction to grass pollen mix.



Besides that, $86 \%$ of the examined patients also have a co-sensitization to tree pollens, particularly to the birch tree family (Fig. 2.).

Fig. 2.Sensitization and degree of skin reaction to pollen allergen from birch trees

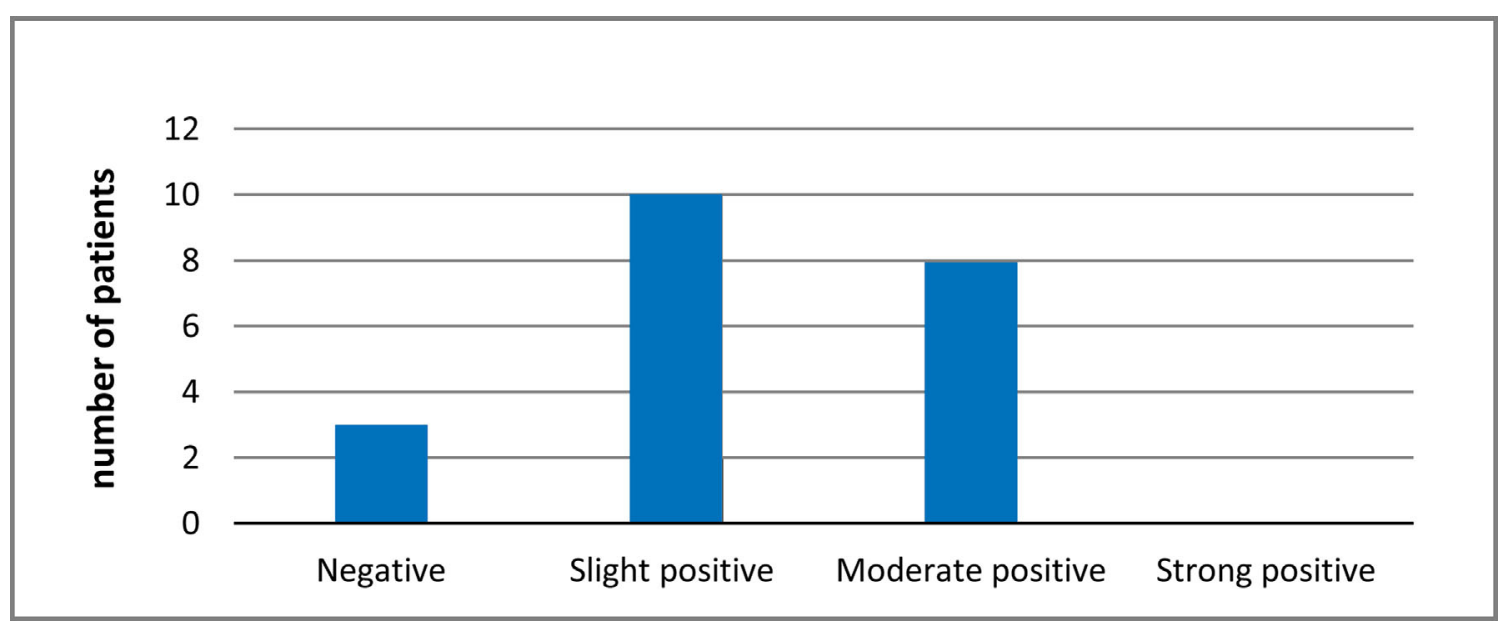

Only $3(14 \%)$ of the studied patients showed slight positive skin tests to the studied plane tree allergens, with no significant difference in sensitization to studied
Platanus species $(\mathrm{p}>0,05)$. In all three cases, they are patients with polysensitization to grass and/or birch pollen (Table 3.)

Table 3.Patients with sensitization to pollen allergens from the studied plane tree species

\begin{tabular}{|l|c|c|c|c|}
\hline \multirow{2}{*}{ Platanus allergens } & \multicolumn{4}{|c|}{ Degree of skin reaction } \\
\cline { 2 - 5 } & Negative & Slight positive & Moderate positive & Strong positive \\
\hline B57-1. Platanusorientalis & $\mathbf{1 8}$ & $\mathbf{3}$ & 0 & 0 \\
\hline B57-2. Platanusacerifolia & $\mathbf{1 9}$ & $\mathbf{2}$ & 0 & 0 \\
\hline B57-3.Platanusoccidentalis & $\mathbf{1 8}$ & $\mathbf{3}$ & 0 & 0 \\
\hline
\end{tabular}




\section{DISCUSSION}

Platanaceae are a family of flowering plants belonging to the Protealesorder. The family contains one single Platanus genus. The following are recognized species of the plane tree: Platanusorientalis L. (Oriental plane); Platanusacerifolia (Aiton) Willd. (London plane) and Platanusoccidentalis L. (American plane),

Plane trees have been used for centuries for urbanistic purposes, due to their ecologic properties, with beneficial results for the public environment.

Platanusorientalis $L$. is the dominant tree species in parks and streets in many cities of the Asian continent, in countries including Iran and China $[11,12]$. In Europe, it can be found in countries such as Italy (drier and warmer climate), Bulgaria (more humid and colder climate), Albania, Greece and Turkey [13].

Platanus $x$ acerifolia (Aiton) Willd. has a considerable impact in large Mediterranean cities [14]. In Spain, for example, plane trees are planted extensively in the green spaces, streets and avenues of both Madrid and Barcelona [15].

As an anemophiloustree, Platanus produces large amounts of pollen during the flowering period (more than four weeks in Spring from April to May in Bulgaria) with an estimate of $3.3 \times 10^{6}$ pollen grains per inflorescence [2, 16] and a threshold of clinical symptoms in individuals sensitized to 50 grains of pollen $/ \mathrm{m}^{3}$ of air [17]. That's why Platanus pollen has been identified by the European Academy of Allergy and Clinical Immunology (EAACI) as an important allergen responsible for respiratory symptoms and was introduced as mandatory to investigate pollen allergen in all patients with suspicion of allergic rhinitis in Europe [18].

Several studies have demonstrated the role of Platanus pollen in respiratory allergies. Platanus $x$ acerifolia (Aiton) Willd. sensitization was 37.9\% in 20092011 and $31.7 \%$ in 20152017 in the 'Panallergens in Pediatrics' study, a large multicenter survey of Italian children with seasonal allergic rhino conjunctivitis (SAR) [19].

A total of 34 patients from 118 subjects with allergic rhinitis presented $\mathrm{IgE}$ specific to Platanus pollen in a Spanish study [20]. Platanusacerifolia (Aiton) Willd. sensitization was present in $11.4 \%$ of patients in an allergic pediatric population of Cova da Beira, Portugal [21]. The percentage of sensitization for Platanus $x$ acerifolia (Aiton) Willd. was $36.6 \%$ in a group of 210 patients with pollinosis [22].

In recent years the number of Platanus trees in Sofia, Bulgaria, has markedly increased. Many young plants were planted near the streets, in parks and in new green areas. Presumably, along with the maturation of these trees, the exposure to plane pollen in the city will also increase. In fact, our regular aerobiological studies show that com- pared to the pollen of the families Betulaceae and Poaceae, the amount of pollen of plane trees is relatively low, but in recent years there has been a tendency for its significant increase - almost twice. This gives rise to a concern for potential allergic epidemics in urban zones in the near future and for producing volatile organic compounds with implications in creating air pollution.

As no studies of sensitization to Platanus pollen have been conducted among Bulgarian patients with pollinosis so far, the current pilot study provides the first data on hypersensitivity to the three most common species of Platanus in Bulgaria: Platanusorientalis L., Platanusoccidentalis L. and Platanus $x$ acerifolia (Aiton) Willd.

Skin allergy tests with specially prepared allergens from pollens of each studied plane tree species showed that compared with the sensitization to grass pollen (95\%) and birch pollen (86\%), the hypersensitivity to the pollen of different species of plane trees is relatively low $14 \%$. The degree of skin reactions is slightly positive, and no species-specificity of sensitization is observed.

Recently Plane trees were used as the first study case for creating a new aerobiological index: The Aerobiological Index of Risk for Ornamental Trees (AIROT). AIROT is a new tool designed to assist in urban planning and the assessment of potential allergenicity for urban green infrastructures. Thus public authorities will try to put in balance the benefits and the pitfalls of using plane trees in urban ecology [23].

\section{CONCLUSION}

The results of this pilot study of patients with pollinosis from Sofia showed that, at present, the sensitization to pollens of different Platanus species is not comparable to that to grass or birch pollen. However, having in mind the high allergenic potential of plane tree pollen, it will be necessary to conduct new long-term, large-scale studies to prove whether Platanus currently pose a real threat to people in urban areas and what is the trend in the future their mass planting to become a serious health problem. This forecast will provide guidelines for assessing the risk of using these species in landscaping and for the design of sustainable green areas with a low risk of allergies.

The results of this interdisciplinary study are important both for clinical allergologists and for landscape architects and ecologists involved in the planning and management of urban green infrastructure.

\section{ACKNOWLEDGEMENTS:}

Acknowledgements for the financial support of Project No B-1149/05.04.21 funded by the Scientific Research Sector at the University of Forestry. 


\section{REFERENCES:}

1. WAO White Book on Allergy. Editors: Pawankar R, Canonica GW, Holgate ST, Lockey RF, Blaiss MS. World Allergy Organization.Update: 2013; 22-109 [Internet]

2.Tormo MR, Munoz RA, Silva PI, Lopez FG. Pollen production in anemophilous trees. Grana. 1996 OctSep;35(1):38-46. [Internet]

3. Damialis A, Fotiou C, Halley JM, Vokou D. Effects of environmental factors on pollen production in anemophilous woody species. Trees. 2011 Apr;25:253-264. [Crossref]

4.Varela S, Subiza J, Subiza JL, Rodriguez R, Garcia B, Jerez M, et al. Platanus pollen as an important cause of pollinosis, JACI. 1997 Dec;100, 6 (1):748-754. [PubMed]

5. Belver MT, Caballero MT, Contreras J, Cabañas R, Sierra E, Madero R, et al. Associations Among Pollen Sensitizations From Different Botanical Species in Patients Living in the Northern Area of Madrid. J Investig Allergol Clin Immunol. 2007; 17(3):157-159. [PubMed]

6. Alonso R, Enrique E, Pineda F, Basagaña M, San Miguel-Moncin M, Bartra J, et al. An Observational Study on Outgrowing Food Allergy during Non-Birch Pollen-Specific, Subcutaneous Immunotherapy. Int Arch Allergy Immunol. 2007;143(3):185-189. [PubMed]

7. Delkov A, GatevaR. Dendrological structure of the green areas in Sofia. In: Ecology of the city of Sofia. Species and communities in urban environment. Editors: Penev L, Niemela L, Kotze DJ, Chipev N. (Eds.). PENSOFT Publishers, Sofia - Moscow. 2004 Jan;213-228. [in Bulgarian]

8. Cariñanos $P$, Ruiz-Peñuela $S$, Valle AM, de la Guardia CD. Assessing pollination disservices of urban streettrees: The case of London-plane tree (Platanus $x$ hispanica Mill. ex Münchh). Science of The Total Environment. 2020 Oct 1;737:139722. [PubMed]
9. Anisimova S. Dendrological diversity in Santa Marina Holiday Village - Sozopol as an example of contemporary landscape design trends in Bulgaria. Silva Balcanica. 2018 Aug; 19(1):5-19.

10. Anisimova S. Inventory of allergenic pollen urban dendroflora as a basis for designing healthier green infrastructure. Forestry Ideas. 2020 Dec; 26(2),60:452-470.

11. Pazouki N, Sankian M, Nejadsattari T, Khavari Nejad RA, Varasteh AR. Oriental plane pollen allergy: Identification of allergens and cross-reactivity between relevant species, Allergy Asthma Proc, 2008 NovDec;29(6):622-628. [PubMed]

12. Jing $X$, Lun $X$, Fan $C$, Ma W. Emission patterns of biogenic volatile organic compounds from dominant forest species in Beijing, China. J Environ Sci (China). 2020 Sep;95:73-81. [PubMed]

13. Rinaldi R, Cafasso D, Strumia S, Cristaudo A, Sebastiani F, Fineschi S. The influence of a relict distribution on genetic structure and variation in the Mediterranean tree, Platanus orientalis. AoB Plants. 2019 Jan 30;11(1),plz002. [PubMed]

14. D'Amato G, Cecchi L, Bonini S, Nunes C, Annesi-Maesano I, Behrendt $\mathrm{H}$, et al. Allergenic pollen and pollen allergy in Europe. Allergy. 2007 Sep; 62(9): 976-990. [PubMed]

15. Gabarra E, Belmonte J, Canela M. Aerobiological behaviour of Platanus L. pollen in Catalonia (NorthEast Spain). Aerobiologia. 2002 Sep; 18(3):185-193. [Crossref]

16. Maya Manzano JM, Fernandez Rodriguez S, Monroy Colín A, Silva Palacios I, Tormo MR, Gonzalo Garijo A. Allergenic pollen of ornamental plane trees in a Mediterranean environment and urban planning as a prevention tool. Urban For Urban Green.2017 Oct;27:352-362. [Crossref]

17. Nowak M, Szymanska A, Grewling L, Allergic risk zones of plane tree pollen (Platanus sp.) in Poznan. Postepy Dermatol Alergol. 2012 Jan;29(3):156-160.

18. Bousquet $\mathrm{J}$, Heinzerling L, Bachert C, Papadopoulos NG, Bousquet PJ, Burney PG, et al. Practical guide to skin prick tests in allergy to aeroallergens. Allergy. 2012 Jan; 67(1):18-24. [PubMed]

19. Cipriani F, Tripodi S, Panetta V, Perna S, Potapova E, Dondi A, et al. Early molecular biomarkers predicting the evolution of allergic rhinitis and its comorbidities: A longitudinal multicenter study of a patient cohort. Pediatr Allergy Immunol. 2019 May;30(3):325334. [PubMed]

20. Fernandez Gonzalez D, Gonzalez Parrado Z, Vega Maray AM, Valencia Barrera RM, Camazón Izquierdo B, De Nuntiis $P$, et al. Platanus pollen allergen, Pla a 1: Quantification in the atmosphere and influence on a sensitizing population. Clin Exp Allergy. 2010 Nov;40(11):17011708. [PubMed]

21. Loureiro G, Rabaça MA, Blanco B, Andrade S, Chieira C, Pereira C, Aeroallergens sensitization in an allergic paediatric population of Cova da Beira, Portugal. Allergol Immunopathol (Madr). 2005 Jul-Aug;33(4):192-198. [PubMed]

22.Cosmes Martin PM, Moreno Ancillo A, Dominguez Noche C, Gutierrez Vivas A, Belmonte Soler J, Roure Nolla JM. Sensitization to Castanea sativa pollen and pollinosis in northern Extremadura (Spain). Allergol Immunopathol (Madr). 2005 MayJun;33(3):145-150. [PubMed]

23. Pecero-Casimiro R, FernándezRodríguez S, Tormo-Molina R, Monroy-Colín A, Silva-Palacios I, Cortés-Pérez JP, et al. Urban aerobiological risk mapping of ornamental trees using a new index based on LiDAR and Kriging: A case study of plane trees. Sci Total Environ. 2019 Nov 25;693:133576. [PubMed]

Please cite this article as: Nikolov G, Tsvetanova R, Hristova-Savova M. A pilot study of sensitization to plane tree pollen in Sofia, Bulgaria. J of IMAB. 2021 Oct-Dec;27(4):4128-4132. DOI: https://doi.org/10.5272/jimab.2021274.4128

\author{
Address for correspondence: \\ Rusana Tsvetanova, \\ University of Forestry, Sofia; V.D. Stoyanov str., 7 bl, A, entr, 28 ap. Sofia, \\ Krasnapolyana, Bulgaria. \\ E-mail: rusanatsvet@gmail.com
}

